\title{
Genome-wide identification, expression analysis and functional study of the GRAS gene family in Tartary buckwheat (Fagopyrum tataricum)
}

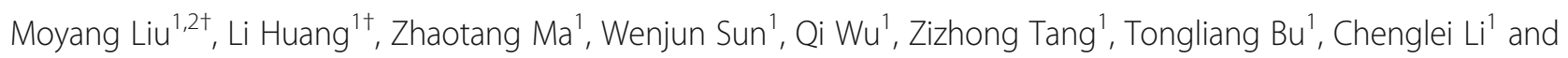
Hui Chen ${ }^{1 *}$ D

\begin{abstract}
Background: GRAS are plant-specific transcription factors that play important roles in plant growth and development. Although the GRAS gene family has been studied in many plants, there has been little research on the GRAS genes of Tartary buckwheat (Fagopyrum tataricum), which is an important crop rich in rutin. The recently published whole genome sequence of Tartary buckwheat allows us to study the characteristics and expression patterns of the GRAS gene family in Tartary buckwheat at the genome-wide level.

Results: In this study, 47 GRAS genes of Tartary buckwheat were identified and divided into 10 subfamilies: LISCL, HAM, DELLA, SCR, PAT1, SCL4/7, LAS, SHR, SCL3, and DLT. FtGRAS genes were unevenly distributed on 8 chromosomes, and members of the same subfamily contained similar gene structures and motif compositions. Some FtGRAS genes may have been produced by gene duplications; tandem duplication contributed more to the expansion of the GRAS gene family in Tartary buckwheat. Real-time PCR showed that the transcription levels of FtGRAS were significantly different in different tissues and fruit development stages, implying that FtGRAS might have different functions. Furthermore, an increase in fruit weight was induced by exogenous paclobutrazol, and the transcription level of the DELLA subfamily member FtGRAS22 was significantly upregulated during the whole fruit development stage. Therefore, FtGRAS22 may be a potential target for molecular breeding or genetic editing.
\end{abstract}

Conclusions: Collectively, this systematic analysis lays a foundation for further study of the functional characteristics of GRAS genes and for the improvement of Tartary buckwheat crops.

Keywords: Tartary buckwheat, GRAS, Genome-wide, Fruit development, Expression patterns

\section{Background}

Transcription factors (TFs) bind to specific DNA sequences (cis-acting elements) in the promoters of target genes, which can promote or inhibit the transcription level of the target genes. TFs play an important role in plant growth and development and response to stress (such as drought, heat, cold and salt) [1-3]. GRAS proteins are plant-specific transcriptional regulators that have been found in recent years [4]. GRAS proteins were named

\footnotetext{
* Correspondence: chenhui@sicau.edu.cn

${ }^{\dagger}$ Moyang Liu and Li Huang contributed equally to this work.

'College of Life Science, Sichuan Agricultural University, Ya'an, China

Full list of author information is available at the end of the article
}

after the first three members of the family, gibberellic acid insensitive (GAI), repressor of GA1-3 mutant (RGA), and scarecrow (SCR) [5-7]. The highly conserved region of the C-terminal region of GRAS proteins is commonly referred to as the GRAS domain. Most members of the GRAS family have only one GRAS domain, but a few GRAS proteins have two GRAS domains, or the Cterminus has another functional domain in addition to one GRAS domain [8]. The GRAS domain can be divided into five units: leucine-rich region I (LHRI), VHIID, leucine-rich region II (LHRII), PFYRE, and SAW [9]. Previous studies have found that LHRI and LHRII play a key role in the homologous dimerization of GRAS protein.

(C) The Author(s). 2019 Open Access This article is distributed under the terms of the Creative Commons Attribution 4.0 International License (http://creativecommons.org/licenses/by/4.0/), which permits unrestricted use, distribution, and 
The VHIID motif is the core structure of the GRAS protein, and P-N-H-D-Q-L in the VHIID motif is very conserved and ends with L-R-I-T-G. The PFYRE motif consists of three parts: P, FY and RE, which may be related to phosphorylation. The SAW motif contains three pairs of conserved amino acid residues R-E, W-G and W-W [9]. However, the N-terminus of GRAS protein is a highly variable region that contains two highly conserved protein structures, DELLA and TVHYNP [10]. The highly variable amino acid sequence of the $\mathrm{N}$-terminus can be folded into a specific molecular recognition structure that binds to the target protein and participates in the signal transduction process [8]. The GRAS gene family is usually divided into 10 subfamilies: DELLA, DLT, HAM, PAT1, LAS, LISCL, SCR, SCL3, SHR and SCL4/7 [8]. For the GRAS family that is gradually being identified in other plants, the family classification is slightly different [8-11]. For example, 93 GRAS genes in populus have been divided into 13 subfamilies (DLT, DELLA, HAM, PAT1, LAS, SHR, LISCL, SCR, SCL3, SCL4/7, Os19, Os4, PT20), of which PT20 are newly discovered [11]. The 50 GRAS genes in pepper are divided into 10 subfamilies (DLT, DELLA, HAM, PAT1, LAS, SCL3, LISCL, SCR, SHR, Os4 and Ca_GRAS), of which Ca_GRAS is a specific subfamily in pepper [2].

As unique transcription factors in plants, GRAS proteins play an important role in plant growth and development [12]. AtSCL13 (PAT1 subfamily) is involved in phytochrome A (phyA) signal transduction, and plays a major role in hypocotyl elongation during the de-etiolation of Arabidopsis thaliana [13]. The expression of GRAS2 (PAT1 subfamily) in tomato was reduced, resulting in a decrease in fruit weight [14]. OsSCR not only participates in the formation of stomata and ligule but also regulates asymmetric division of cells [15]. The PhHAM gene in Petunia is mainly expressed in the primordia of lateral organs and stem provascular tissues. The PhHAM gene acts on adjacent tissues in a noncellular autonomous way to maintain the activity of the apical meristem [16]. NSP1 (SHR subfamily) and NSP2 (HAM subfamily), form a DNA binding complex to induce gene expression during nodulation signaling in Medicago truncatula [17]. The mutation of the DLT/OsGRAS-32 gene in rice results in the decrease in GA content and plant dwarfing [18]. SCL3 and DELLA balance gibberellin feedback regulation via IDD proteins [19]. In addition to participating in plant growth and development, members of the GRAS family are also involved in plant responses to various abiotic stresses. Gh_A01G0682 and Gh_A04G0081 are upregulated under salt and PEG stress [20]. MtGRAS32 and MtGRAS60 are positively upregulated but MtGRAS47 and MtGRAS45 downregulated after GA3 treatment [21]. Until now, the regulatory mechanism of DELLA proteins in the GRAS gene family has been studied extensively and thoroughly. DELLA proteins are the main negative regulators of gibberellin (GA) signal transduction. Research in Arabidopsis thaliana suggests that GA regulates late embryo development by regulating DELLA protein levels [22]. By decreasing DELLA activity, it can promote the growth of parthenocarpic fruits in tomato [23]. The interaction between DELLA and ARF/IAA mediates the crosstalk between gibberellin and auxin signaling to control the initiation of tomato fruit [24]. There is only one DELLA protein SLR1 in rice, and GA signals promote cellulose synthesis by relieving the interaction between SLR1 and NACs [25].

Tartary buckwheat is a dicotyledonous plant in the Polygonaceae family that contains a variety of nutrients, especially flavonoids such as rutin and quercetin [26]. Until now, transcription factor families such as ARF, MADS, AP2/ ERF, NAC, bZIP, ZF-HD have been identified in Tartary buckwheat [27-32]. More importantly, through in-depth research of $A R F 2$, it has been found that $A R F 2$ plays an important role in determining the final size of Tartary buckwheat fruit [33]. The GRAS gene family has been widely studied in many plants, such as Arabidopsis thaliana, rice, tomato, pepper, maize and Chinese cabbage [2, 11, 34-37]. However, few studies have examined GRAS proteins in Tartary buckwheat. Due to the important role of GRAS genes in various physiological processes, study of the Tartary buckwheat GRAS gene family is important. The recent complete genome sequencing of Tartary buckwheat provides researchers an opportunity to reveal the tissue expression profile and evolution of the GRAS gene family in Tartary buckwheat [38]. In this study, we first analyzed the gene structure, chromosomal location, duplication events of 47 FtGRAS genes, and motif composition, 3D structure of 47 FtGRAS proteins. We then compared the evolutionary relationship with 7 species (Arabidopsis thaliana, rice, soybean, grape, tomato, sunflower, beet). Next, the expression patterns of the FtGRAS genes in different tissues and different fruit development stages were determined. Finally, we further explored the relationship between DELLA and Tartary buckwheat fruit development. In summary, this research provides valuable clues for the functional characterization of members of the GRAS gene family during the growth and development of Tartary buckwheat.

\section{Results}

\section{Identification of FtGRAS genes in Tartary buckwheat}

In this study, 47 FtGRAS genes were identified from the Tartary buckwheat genome. They were then renamed FtGRAS1 to FtGRAS47 according to their chromosomal location (Additional file 3: Table S1). The basic characteristics were analyzed, including the coding sequence length (CDS), protein molecular weight $(\mathrm{Mw})$, isoelectric point (pI) and subcellular localization (http://cello.life. nctu.edu.tw/) (Additional file 3: Table S1). Of the 47 FtGRAS proteins, FtGRAS7 was the smallest protein 
with 44 amino acids, and the largest protein was FtGRAS1 with 755 amino acids. The Mws of the proteins ranged from $5.19 \mathrm{kDa}$ (FtGRAS1) to $83.5 \mathrm{kDa}$ (FtGRAS7), and the pI ranged from 4.85 (FtGRAS19) to 9.72 (FtGRAS39), with a mean of 6.45. The CDSs of the FtGRAS genes varied greatly, ranging from 132 to 2265 bp. The CDS of FtGRAS7 was the shortest at 132 bp, and the CDS of FtGRAS1 was the longest, reaching $2265 \mathrm{bp}$. The predicted subcellular localization results showed that 19 FtGRAS proteins were located in the nuclear region, 14 in the cytoplasm, 8 in the plasma membrane, 3 in the chloroplast, and 3 in the mitochondria.

\section{Phylogenetic analysis and classification of FtGRAS genes}

To explore the phylogenetic relationship of GRAS protein in Tartary buckwheat, we constructed a phylogenetic tree using the Maximum Likelihood (ML) method based on the amino acid sequences of 47 FtGRAS and 31 AtGRAS proteins (Fig. 1). According to their homology with GRAS proteins in Arabidopsis thaliana, the 47 GRAS genes of Tartary buckwheat were divided into
10 subfamilies: LAS, SCL4/7, HAM, SCR, DLT, SCL3, DELLA, PAT1, SHR, and LISCL. The LISCL subfamily had the largest number of members, with 19 FtGRAS genes. The SCL4/7, LAS, and DLT subfamilies all contained only one member, and there were $10,6,3,2,2$, and 2 FtGRAS genes in HAM, PAT1, DELLA, SCR, SHR, and SCL3, respectively (Fig. 1).

\section{Gene structure and motif composition of the FtGRAS gene family}

To understand the structural components of the FtGRAS genes, the exon and intron structures of the FtGRAS genes were obtained by comparing the corresponding genomic DNA sequences (Fig. 2b). Forty-seven FtGRAS genes all contained the GRAS domain, and most of the FtGRAS genes $(41, \sim 87 \%)$ contained no introns; FtGRAS18, FtGRAS31, FtGRAS34, FtGRAS37 and FtGRAS38 contained one intron, and only FtGRAS20 contained two introns. In general, members of the same subfamily had similar gene structures.

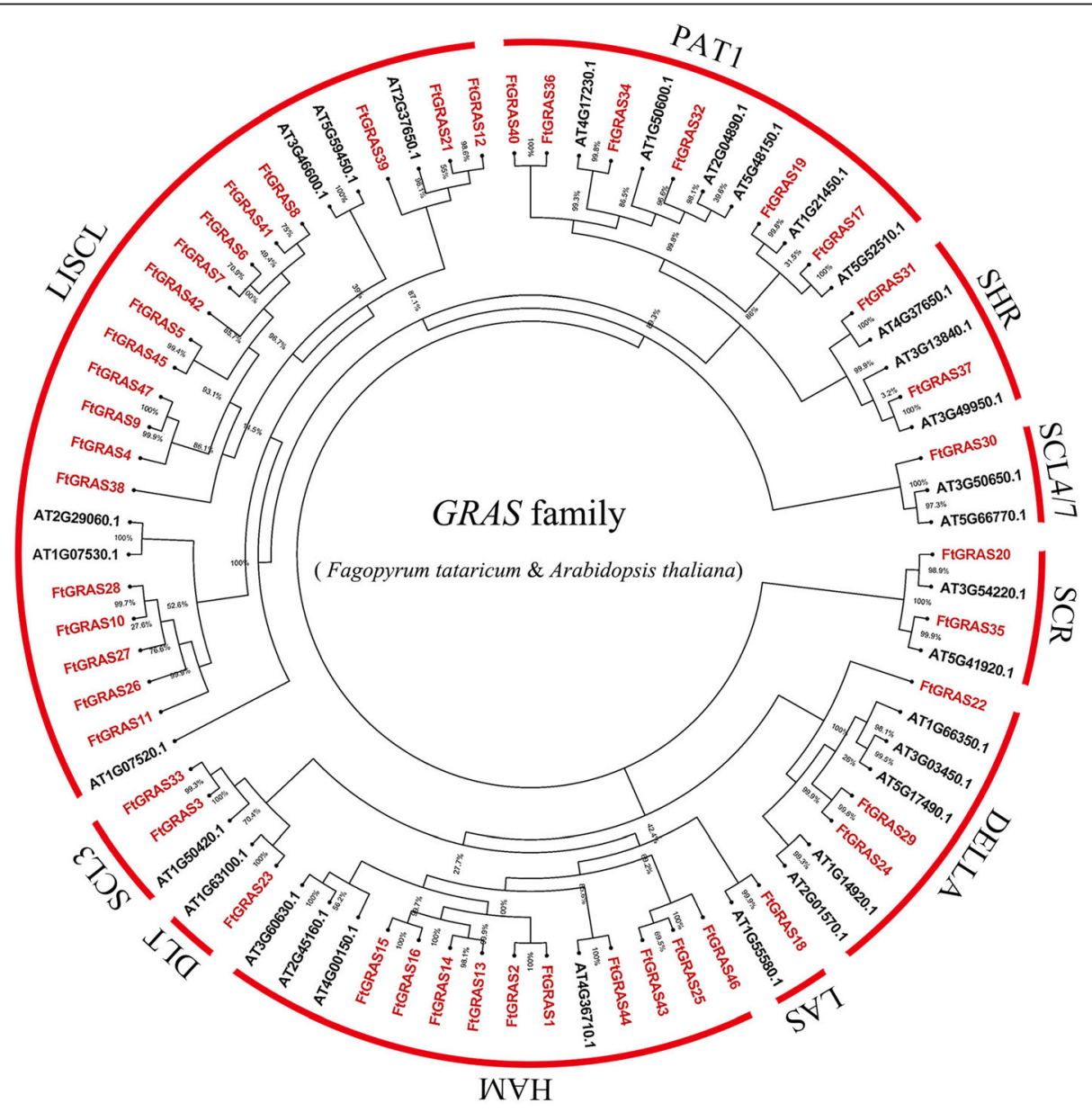

Fig. 1 Phylogenetic tree representing the relationships among GRAS of Tartary buckwheat and Arabidopsis thaliana used the Maximum Likelihood (ML) method 


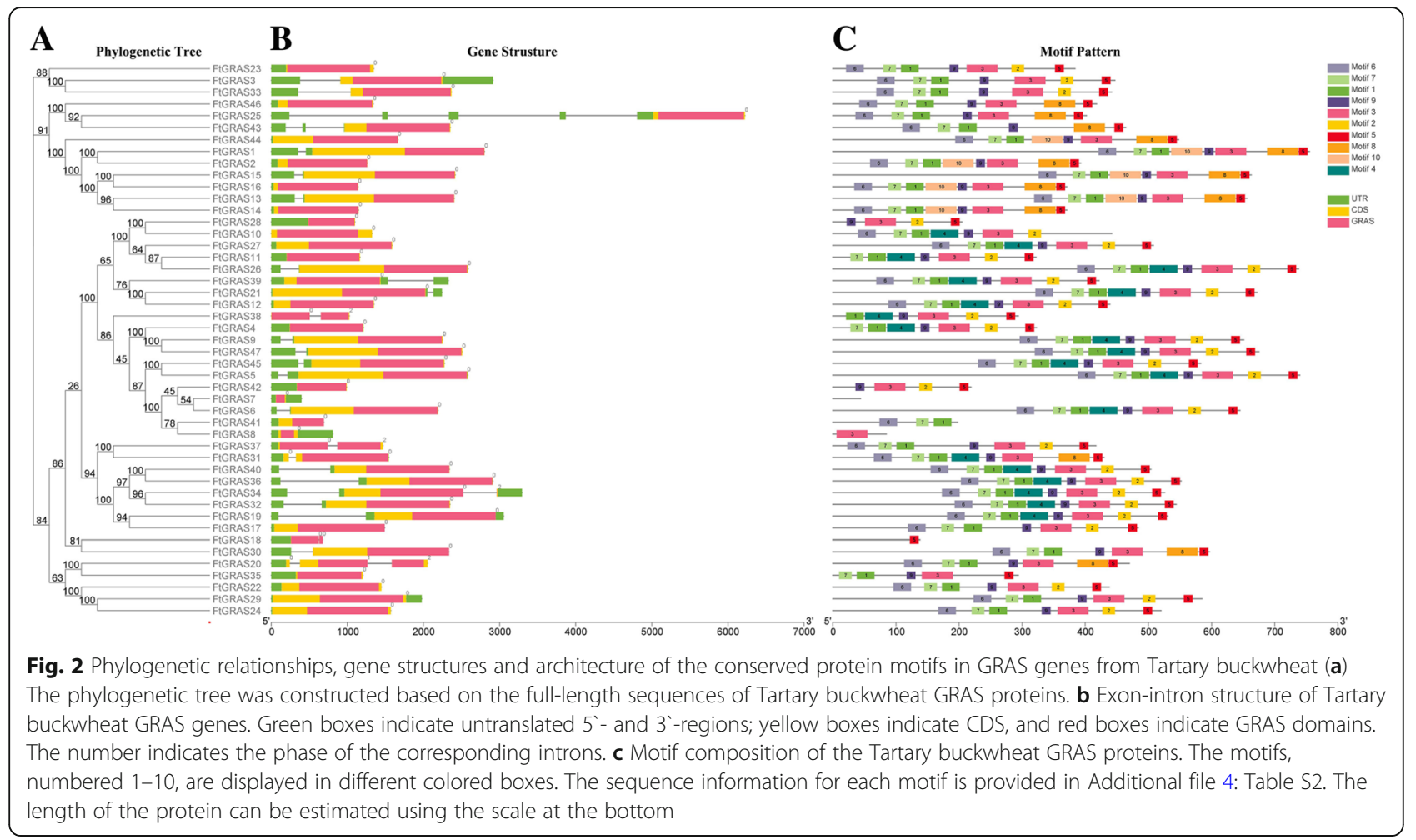

To further study the characteristic region of the FtGRAS proteins, the motifs of 47 FtGRAS proteins were analyzed using an online MEME (Fig. 2c). A total of 10 distinct conserved motifs (named Motif 1-10) were found (Fig. 2c; Additional file 4: Table S2). The motifs were arranged according to the sequence of domains, with motif 6 belonging to the LHRI domain, motif 7 and 1 belonging to the VHIID domain, motif 4 and 9 belonging to the LHRII domain, motif 3 belonging to the RFYRE domain, motif $2,8,5$ belong to the SAW domain. Motif 10 was distributed between motif 1 and motif 4 . Most of the FtGRAS proteins (89\%) contained motif 3 and motif 5 . FtGRAS7 did not contain any motif, FtGRAS8 contained only motif 3 , and FtGRAS18 contained only motif 5 . Simultaneously, we found that some motifs were only present in specific subfamilies. For instance, motif 4 was only present in LISCL, SHR and PAT1, and motif 10 only in HAM. When the FtGRAS gene family members were compared, the results showed that most of the closely related members had similar motifs. For example, the SCL3 group contained motifs $6,7,1,9,32$, and 5 , but the DELLA group contained motifs $6,7,1,4,9,3$, and 2.

Protein models of all the 47 FtGRAS were built using SWISS-MODEL (Additional file 1: Figure S1), and the results showed that the tertiary structures of FtGRAS protein mainly contained $\alpha$-helices and random coils. The six proteins (FtGRAS7, 8, 18, 34, 41, 42) contained fewer $\alpha$-helices and random coils (Additional file 1: Figure S1). Overall, the conserved motif composition and similar gene structures within the same groups of GRAS members, coupled with the results of the phylogenetic analysis, supported the reliability of the population classification.

\section{Chromosomal distribution and synteny analysis of FtGRAS genes}

A map of the physical position of the FtGRAS genes was created based on the physical location information of the Tartary buckwheat genome (Fig. 3). According to the result, the FtGRAS genes were unevenly distributed on 8 chromosomes of Tartary buckwheat. Ft1 had the most FtGRAS genes (12, 26\%), followed by Ft2 (10, 21\%), Ft7 (8, 17\%), Ft3 (6, 13\%), Ft5 (5, 11\%), Ft4 (3, $6 \%)$, Ft6 (2, 4\%) and Ft8 containing only one GRAS gene $(\sim 2 \%)$. Interestingly, the number of GRAS genes distributed in the middle of the 8 chromosomes in Tartary buckwheat was relatively low, and the distribution of the GRAS gene on the chromosomes was similar to ATGRAS and OsGRAS [10].

In addition, we analyzed the duplication events of the FtGRAS genes because gene duplication plays an important role in the occurrence of new functions and the amplification of the gene family (Fig. 3; Fig. 4). Chromosomal regions within a $200 \mathrm{~kb}$ range of two or more genes were defined as tandem duplication events [39]. Twelve FtGRAS genes were clustered into eight tandem duplication event regions in Tartary buckwheat chromosomes 1 , 2, and 3, indicating that they were hot spots for FtGRAS 


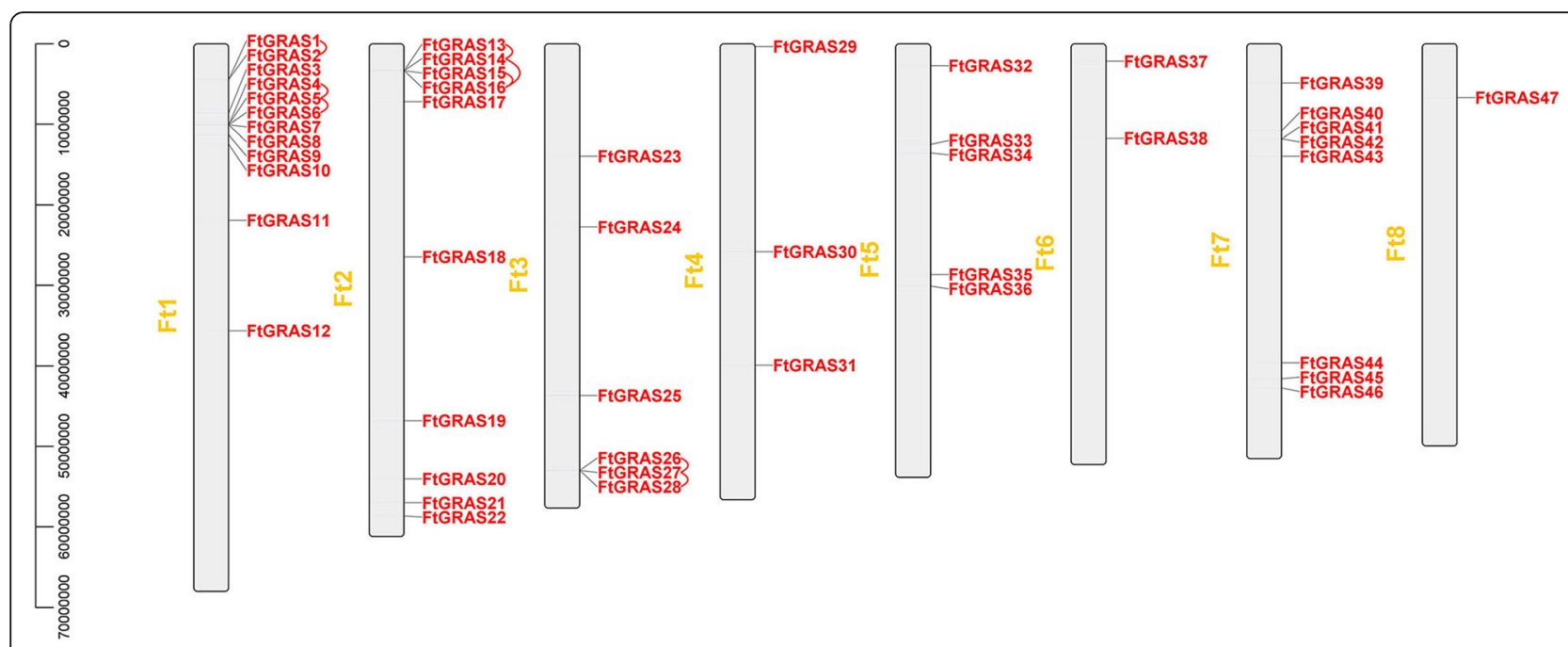

Fig. 3 Schematic representations of the chromosomal distribution of Tartary buckwheat GRAS genes. The red lines indicate duplicated GRAS gene pairs. The chromosome number is indicated to the left of each chromosome

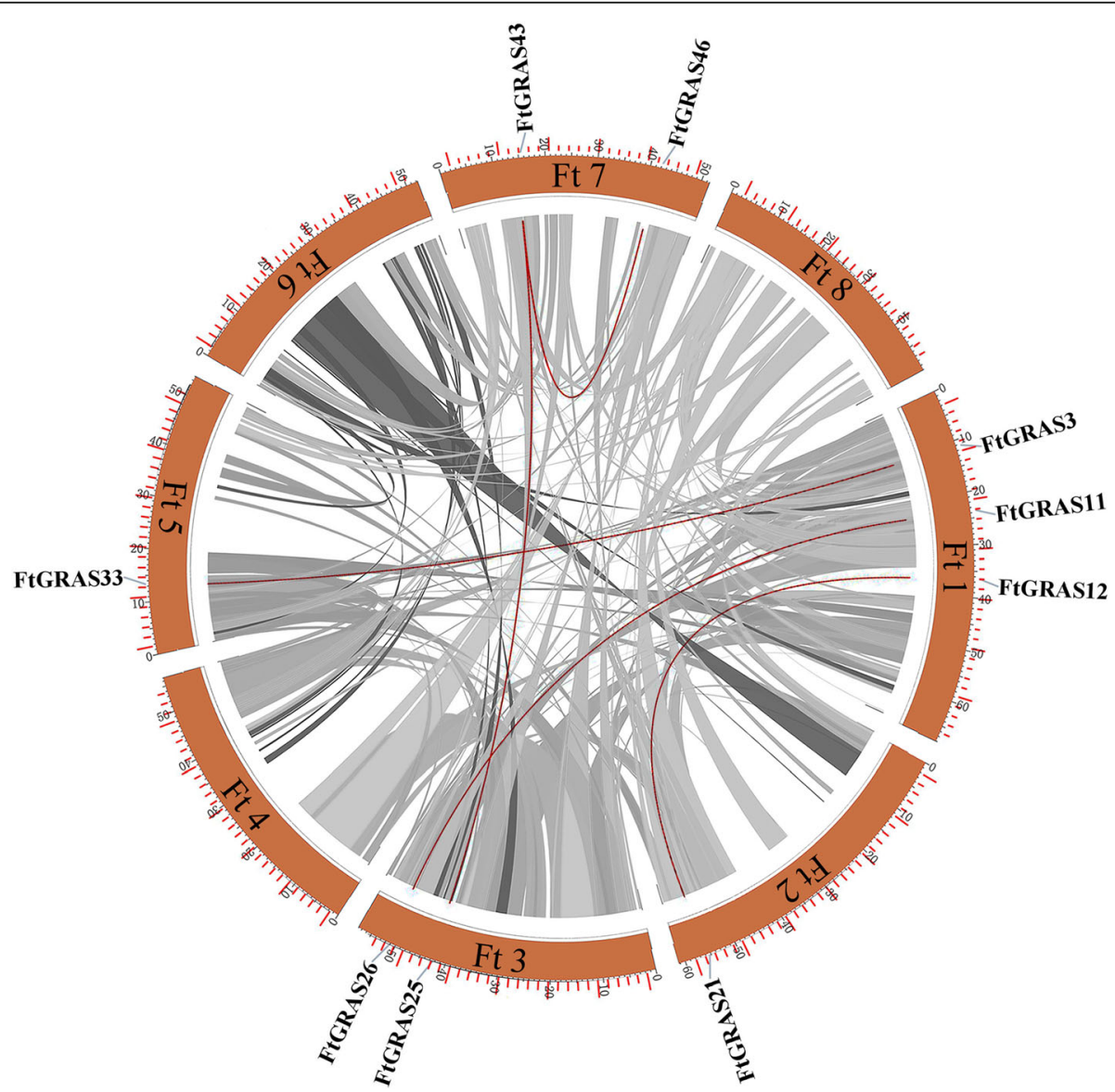

Fig. 4 Schematic representations of the inter-chromosomal relationships of Tartary buckwheat GRAS genes. Gray lines indicate all syntenic blocks in the Tartary buckwheat genome, and red lines indicate duplicated GRAS gene pairs 
gene distributions (Fig. 3). Ft1 had three clusters (FtGRAS1/FtGRAS2, FtGRAS4/FtGRAS5, FtGRAS5/ FtGRAS6), Ft2 also had three clusters (FtGRAS13/ FtGRAS14, FtGRAS14/FtGRAS16, FtGRAS15/FtGRAS16), and Ft3 had two clusters (FtGRAS26/FtGRAS27, FtGRAS27/FtGRAS28). At the same time, five pairs of segmental duplication events were detected between 5 chromosomes: Ft1 (FtGRAS112)/Ft2 (FtGRAS21), Ft1 (FtGRAS11)/Ft3 (FtGRAS26), Ft1 (FtGRAS3)/Ft5 (FtGRAS33), Ft3 (FtGRAS25)/Ft7 (FtGRAS43) and Ft7 (FtGRAS43)/Ft7 (FtGRAS46) (Fig. 4). There were no segmental duplication gene pairs on $\mathrm{Ft} 4,6$, 8. In conclusion, the FtGRAS gene tandem duplication and segmental duplication events occurred mainly in HAM and LISCL. Simultaneously, we carried out a synteny analysis of the Tartary buckwheat GRAS genes (Fig. 4). Most of the genes in Tartary buckwheat were kept in collinear blocks, suggesting that the GRAS gene family of Tartary buckwheat had a high degree of retention on the corresponding chromosomes during evolution [40]. Concisely, these results suggested that certain FtGRAS genes may have been produced by gene duplication and that tandem duplication events may have been the main driving force of FtGRAS evolution.

\section{Evolutionary analysis of FtGRAS genes and GRAS genes of several different species}

Based on the existing Tartary buckwheat GRAS genes, the diversity of the GRAS gene family during evolution Was further studied. A phylogenetic tree was constructed using the GRAS protein sequences of seven dicotyledonous plants (Arabidopsis thaliana, beet, soybean, grape, tomato, sunflower and Tartary buckwheat) and one monocotyledonous plant (rice). Concurrently, the motifs of the 8 plant GRAS proteins were determined (Fig. 5; Additional file 4: Table S2).

The number of GRAS gene and genome size of seven species were soybean $(139,1.025 \mathrm{~Gb})$ [41], rice (60, $389.77 \mathrm{Mb}$ ) [42], tomato (53, $900 \mathrm{Mb})$ [43], Tartary buckwheat (47, 489.3 Mb) [38], grape (43, 427.2 Mb) [44], Arabidopsis thaliana, (32, $125 \mathrm{Mb}$ ) [45], beet (28, 394.6 $\mathrm{Mb}$ ) [46], and sunflower (9, 3.6 Gb) [47], respectively. Among the seven species, Arabidopsis thaliana has the smallest genome, but the number of GRAS genes was not the least; sunflower had the largest genome, but the number of GRAS genes was not the largest. Therefore, there is no positive correlation between genome size and the number of GRAS genes of these species. We also used MEME web servers to search for conserved motifs that were shared among the GRAS proteins, and ten different conserved motifs were found (Motif 1-10) (Fig. 5; Additional file 4: Table S2). Arrangement of the motifs according to the sequence of domains showed that motif
7 belonged to the LHRI domain, motifs 6,2 , and 8 to the VHIID domain, motif 9 to the LHRII domain, motifs 3 and 1 to the RFYRE domain, and motif 5 to the SAW domain. Motif 10 was distributed between motif 9 and motif 3 , and motif 4 was distributed between motif 1 and motif 5. Almost all GRAS proteins contained motif 7. GRAS members in the same clade, especially the most closely related members, usually shared common motifs, indicating potential functional similarities between GRAS proteins.

To further deduce the phylogenetic mechanism of the Tartary buckwheat GRAS gene family, we constructed seven representative comparative systematic maps with Tartary buckwheat, including six dicotyledonous plants (Arabidopsis thaliana, soybean, grape, tomato, beet and sunflower) and one monocotyledonous plant (rice) (Fig. 6; Additional file 5: Table S3). A total of 27 FtGRAS genes showed syntenic relationships with those in soybean, followed by tomato (21), grape (18), beet (16), Arabidopsis thaliana (8), sunflower (6) and rice (5). The number of homologous pairs of the other 7 species (soybean, tomato, grape, beet, Arabidopsis thaliana, sunflower and rice) were 57, 29, 28, 19, 13, 6 and 6, respectively. The FtGRAS gene had the most syntenic gene pairs with soybean, FtGRAS19, FtGRAS31, FtGRAS34, and FtGRAS40 had four syntenic gene pairs with soybean, and FtGRAS21 had six syntenic gene pairs with soybean. In addition, FtGRAS21 had syntenic genes with GRAS genes in another five plants (tomato, grape, beet, sunflower and rice), suggesting an important role of FtGRAS21 in gene evolution.

\section{Expression patterns of the FtGRAS genes in different plant tissues}

An evolutionary analysis of the FtGRAS gene of several different species was carried out, and 28 genes that may have potential research value were selected (Fig. 7; Additional file 5: Table S4;). To investigate the physiological role of these FtGRAS genes, real-time PCR was used to analyze the transcription products of the 28 FtGRAS genes in the root, stem, leaf and flower (Fig. 7a). Most of the genes were highly expressed in root, 4 genes (FtGRAS9, FtGRAS22, FtGRAS25, FtGRAS35) were highly expressed in both stem and flower, 2 genes (FtGRAS12 and FtGRAS32) were highly expressed in fruit, and 2 genes (FtGRAS21 and FtGRAS23) were highly expressed in flower. We also found that FtGRAS10 was not expressed in stem and FtGRAS37 was not expressed in leaf and fruit. The results showed diverse transcriptional abundance of FtGRAS genes in different tissues and organs, indicating that the FtGRAS genes had multiple functions in the growth and development of Tartary buckwheat.

Concomitantly, we analyzed the correlations among the FtGRAS gene expression patterns (Fig. 7b). A large proportion of FtGRAS gene expression was positively 


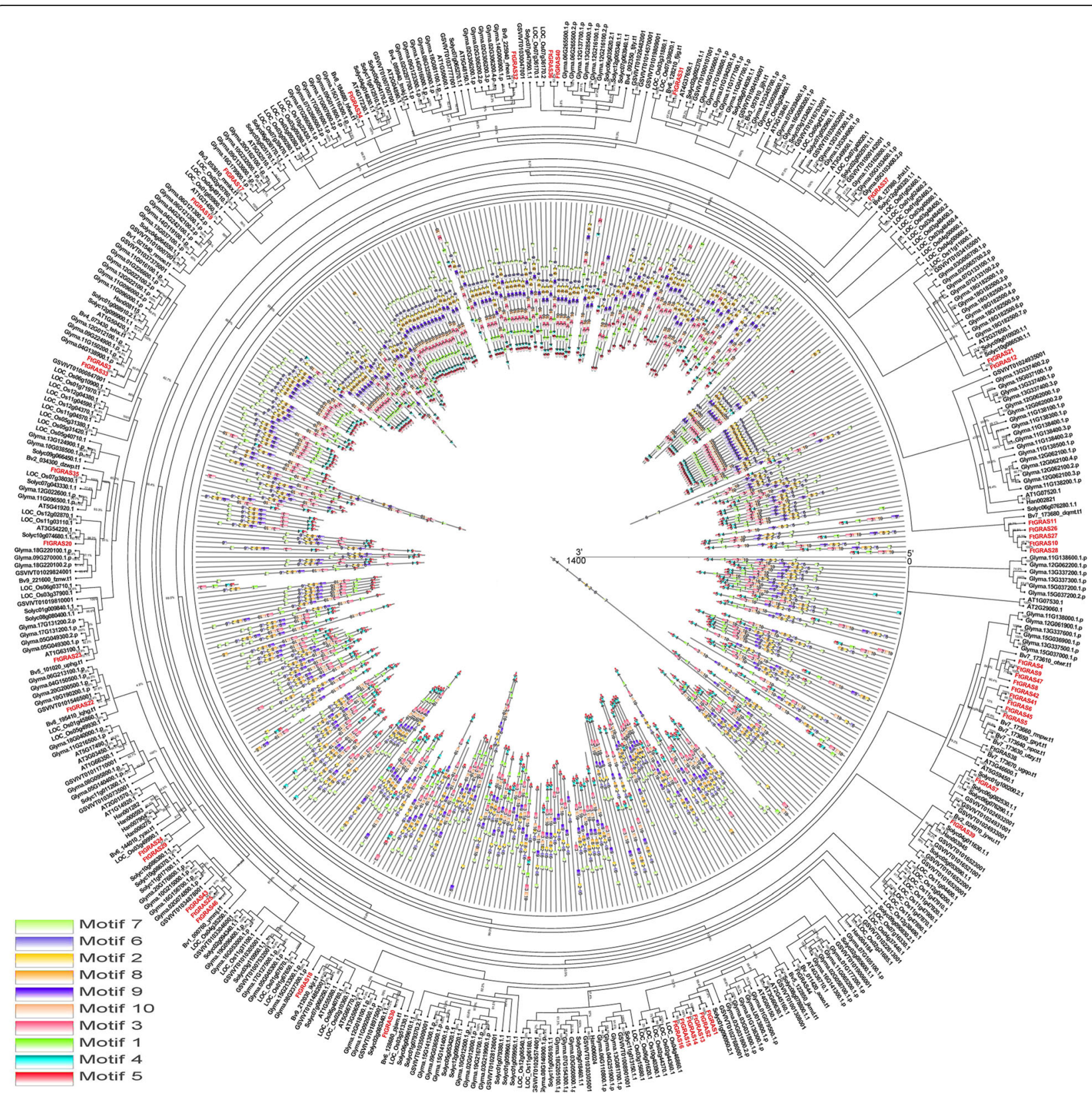

Fig. 5 Phylogenetic relationships and motif compositions of GRAS proteins from eight different plant species. The GRAS genes from Tartary buckwheat and other plant species are marked in red and black, respectively. The percentages beside all branches are bootstrap support values generated from 1000 replicates. The motifs, numbered 1-10, are displayed in different colored boxes. The sequence information for each motif is provided in Additional file 4: Table S2

correlated, and some FtGRAS genes, such as FtGRAS24/ FtGRAS27 (0.921), FtGRAS12/FtGRAS24 (0.980), and FtGRAS1/FtGRAS22 (0.947), were significantly correlated.

\section{Differential expression of FtGRAS genes during fruit development of Tartary buckwheat}

The main edible part of Tartary buckwheat is the fruit, which is known for its high content of rutin. Rutin can effectively prevent liver damage and cardiovascular and cerebrovascular diseases [48]. A few reports have examined the gene regulatory networks that regulate the physiological changes during the development of Tartary buckwheat fruit that are supported by the genome of Tartary buckwheat. Therefore, it is important to study the expression patterns of FtGRAS genes during the development of Tartary buckwheat fruit. By exploring the expression patterns of the FtGRAS gene in different plant tissues, we further selected 

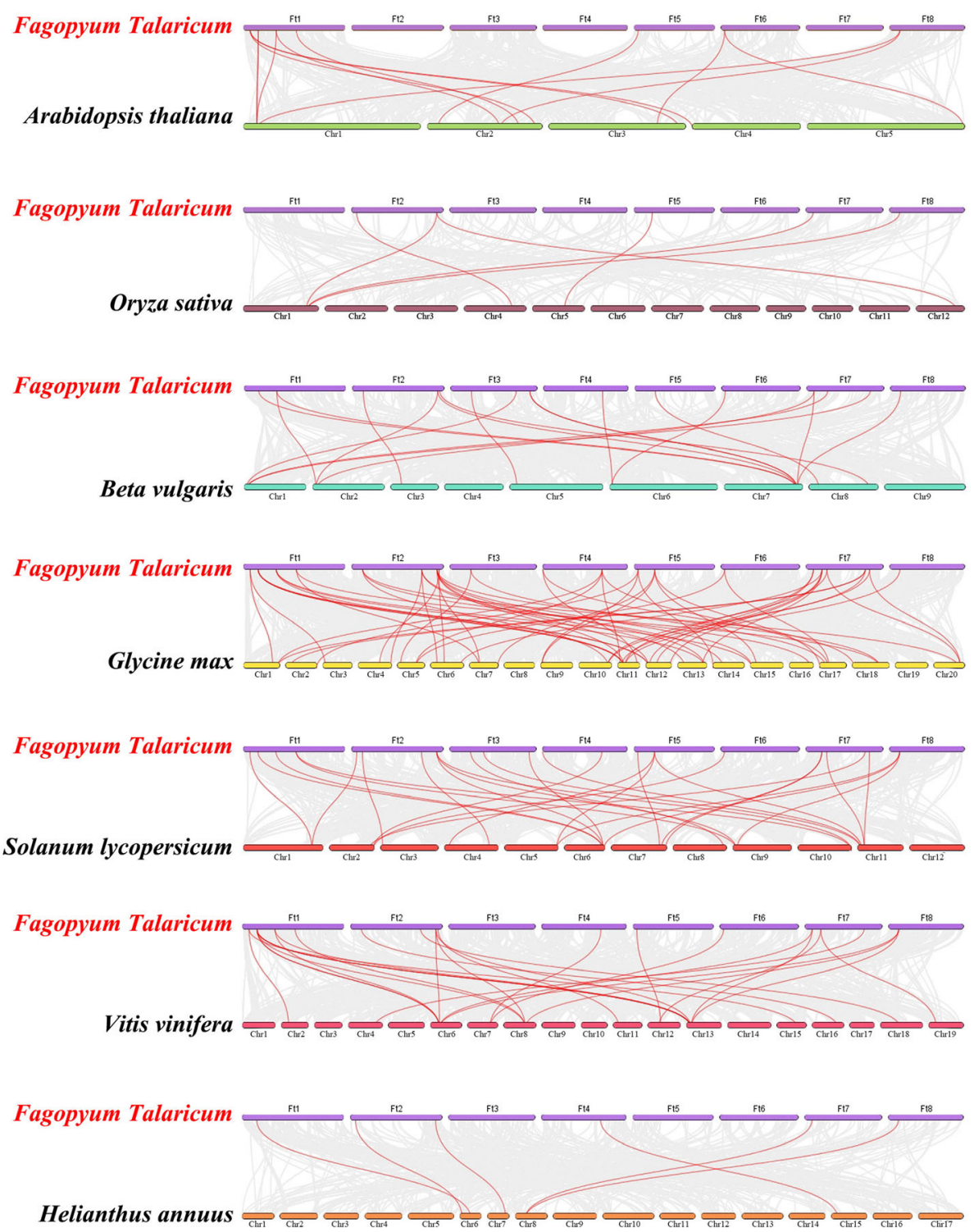

Fig. 6 Synteny analysis of the GRAS genes between Tartary buckwheat and seven representative plant species. Gray lines in the background indicate the collinear blocks within Tartary buckwheat and other plant genomes, while red lines highlight the syntenic FtGRAS gene pairs

26 genes that might be related to fruit development (Fig. 8a). According to previous reports, the green fruit stage (8-14 DAP), discoloration stage (14-22 DAP), and initial maturity stage (22-26 DAP) represent the early, middle and late stages of buckwheat fruit development, respectively [49]. We used real-time PCR to detect the expression of the 26 FtGRAS genes at 13, 19 and 25 days after pollination (DAP) (Fig. 8a). The results showed that most of the genes were highly expressed at 13DAP, and 4 genes (FtGRAS5, FtGRAS12, FtGRAS29, FtGRAS32) were highly expressed at 25DAP. Two genes (FtGRAS4, FtGRAS46) maintained a relatively stable expression level during fruit development.

FtGRAS gene expression was negatively correlated with fruit development, except for FtGRAS5, FtGRAS12,
FtGRAS29, FtGRAS32, FtGRAS38, and FtGRAS46. By analyzing the correlations among the FtGRAS gene expression patterns (Fig. $8 \mathrm{~b}$ ), we found that most the FtGRAS gene expression was positively correlated, and some FtGRAS genes, such as FtGRAS24/FtGRAS27 (0.997), FtGRAS24/FtGRAS40 (1.000), and FtGRAS9/ FtGRAS22 (1.000) were significantly correlated.

\section{Expression of DELLA subfamily genes after paclobutrazol treatment}

DELLA protein, as the main negative regulator of GA signal transduction, may play an important role in the development of Tartary buckwheat fruit [22, 50]. To further study the relationship between DELLA subfamily genes 


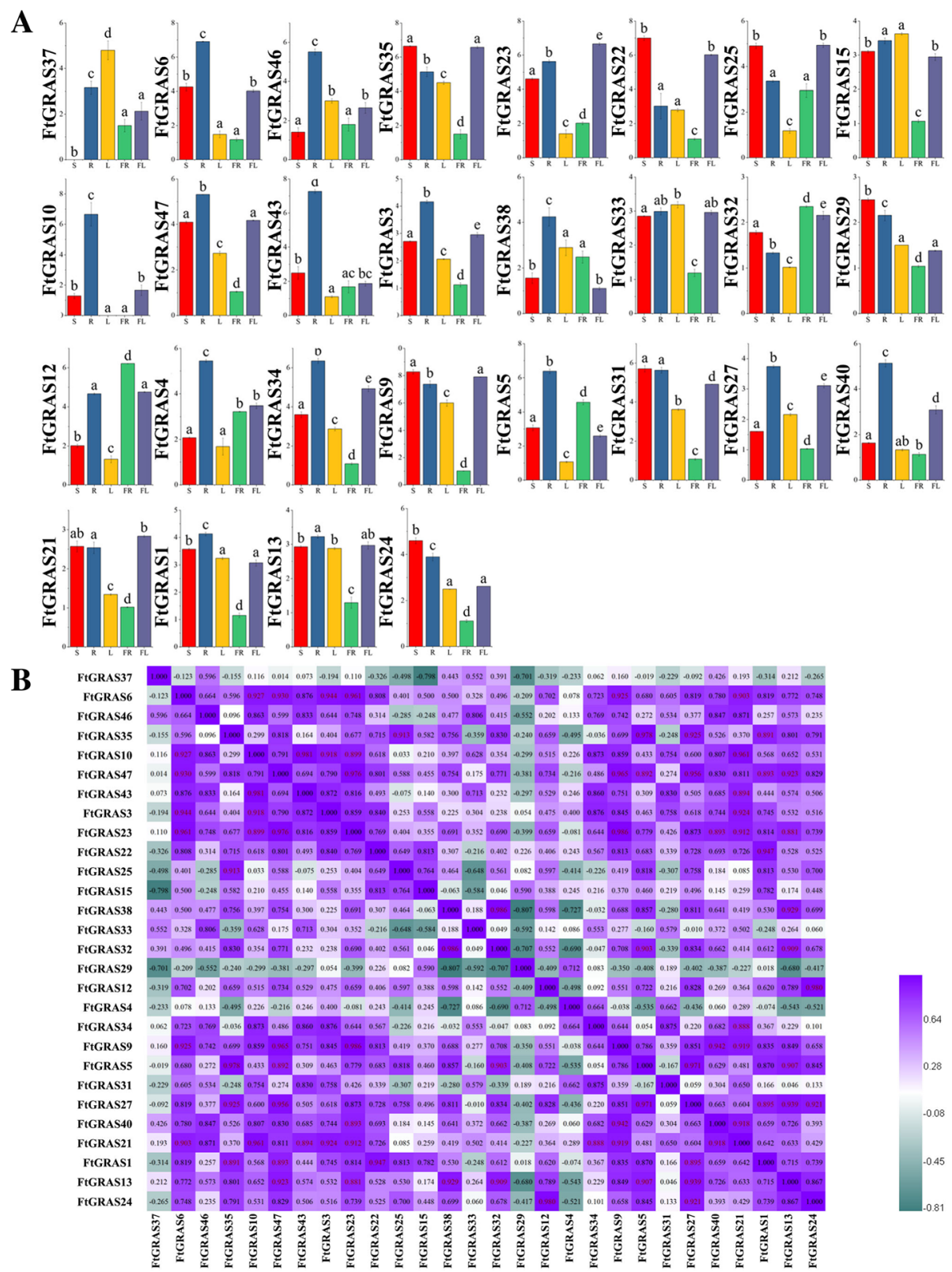

Fig. 7 Tissue-specific gene expression of 28 Tartary buckwheat GRAS genes. (A) The expression patterns of 28 Tartary buckwheat GRAS genes in the flower, leaf, root, stem and fruit tissues were examined by a qPCR assay. Error bars were obtained from fifteen measurements. Lowercase letter(s) above the bars indicate significant differences $(a=0.05, L S D)$ among the treatments. (B) The correlation between the gene expression patterns of FtGRAS. Purple: positively correlated; green: negatively correlated

(FtGRAS22, FtGRAS24, FtGRAS29) and fruit development of Tartary buckwheat, we first measured the changes in endogenous GA. Then, we applied paclobutrazol, a triazole plant growth regulator and an inhibitor of endogenous GA synthesis, to affect fruit development [51, 52].

We found that the endogenous GA content decreased from 13 to 19 DAP and increased at 19-25 DAP (Fig. 9a). Different concentrations of paclobutrazol (80, 120, 160, 120, and $240 \mathrm{mg} \mathrm{L}^{-1}$ ) were sprayed on Tartary buckwheat at the bud stage (Fig. 9b). The results showed that the fresh weight of mature fruit increased significantly to $24.58 \mathrm{mg}$ after 160 $\mathrm{mg} \mathrm{L}^{-1}$ paclobutrazol treatment, which was $106 \%$ of the blank group $(23.22 \mathrm{mg})$. When the concentration of paclobutrazol was higher or less than $200 \mathrm{mg} \mathrm{L}^{-1}$, there was no significant effect on fruit weight gain, and concentration that too high would reduce fruit weight (Fig. 9b). After spraying $160 \mathrm{mg} \mathrm{L}^{-1}$ paclobutrazol, the fruit size increased during the whole fruit development stage (Fig. 9c). We then further explored the effect of exogenous application of $160 \mathrm{mg} \mathrm{L}^{-1}$ paclobutrazol on the expression of the DELLA subfamily 


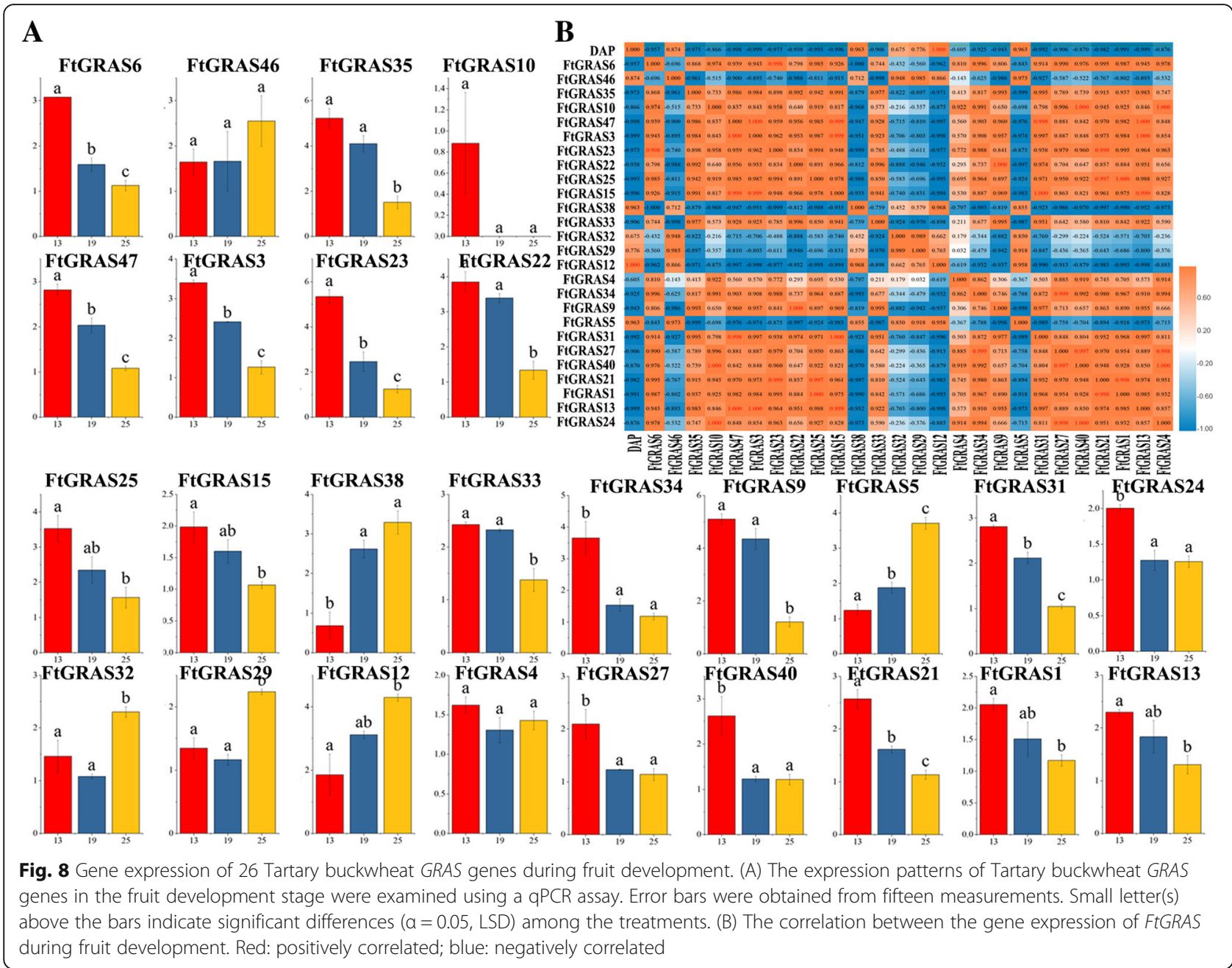

genes (FtGRAS22, FtGRAS24, FtGRAS29). Paclobutrazol treatment $(5 \mathrm{~mL})$ was used as the experimental group and the same amount of water treatment as the control group. The changes in expression of DELLA genes (FtGRAS22, FtGRAS24, FtGRAS29) under different treatments were compared (Fig. 9d). The expression levels of the three genes in the fruit development stage changed greatly after treatment with exogenous paclobutrazol. Compared with the control group, FtGRAS29 expression decreased at 13DAP, increased significantly at 19DAP, and decreased significantly at 25DAP. FtGRAS24 expression increased at 13 DAP but decreased at 19 DAP and 25 DAP. It is worth noting that after treatment with exogenous paclobutrazol, the expression of FtGRAS22 increased significantly during the whole fruit development stage. In summary, among the three genes, the responses of FtGRAS22 and FtGRAS29 to external paclobutrazol were more obvious, especially FtGRAS22.

\section{Discussion}

GRAS transcription factors play vital roles in regulating plant growth and development [12]. With the development of biotechnology and bioinformatics, the GRAS gene family has been identified and analyzed in many plants, such as Arabidopsis thaliana, rice, tomato, and pepper. The whole genome sequence of Tartary buckwheat has been identified, but there are few reports on GRAS in Tartary buckwheat. In this study, we systematically analyzed the GRAS gene family in Tartary buckwheat.

\section{FtGRAS gene structure and evolutionary analysis}

A total of 47 FtGRAS genes were obtained from the Tartary buckwheat genome. The number of FtGRAS genes in Tartary buckwheat is higher than that in Arabidopsis thaliana (32) [10], close to that in Chinese cabbage (48) [37], castor beans (48) [53] and pepper (50) [2], and less than that in tomato (53) [34], rice (60), [10], and poplar (106), [11]. Some studies have shown that the origin of the plant GRAS gene family derived from the prokaryotic genome through horizontal gene transfer, followed by duplication events [54]. Therefore, the changes in the number of GRAS genes may be associated with gene 


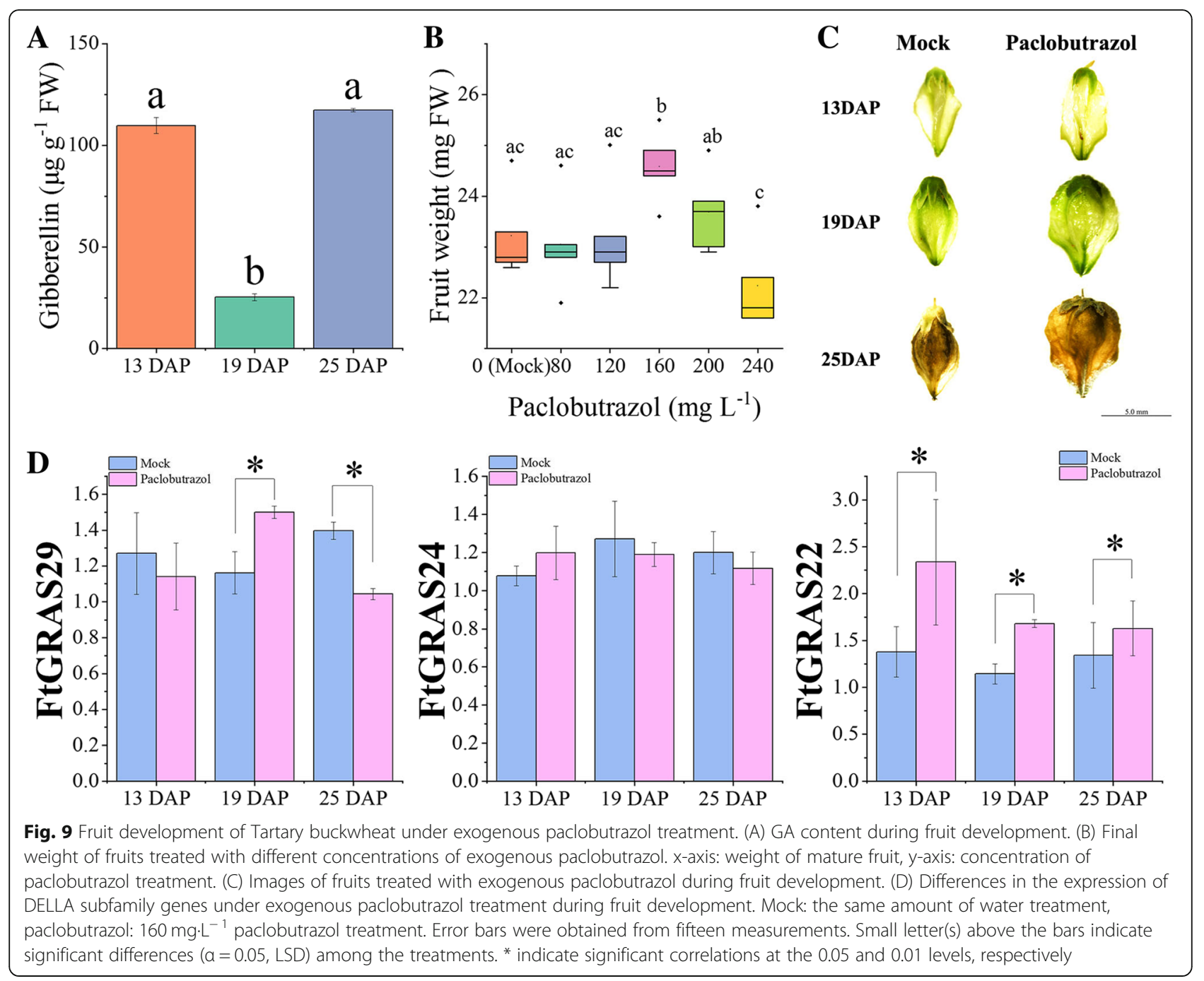

duplication events. Based on previous research, 2/34, 15/ $53,12 / 5017 / 60$, and 40/106 were identified as tandem duplicated genes in Arabidopsis thaliana [10], tomato [34], pepper [2], rice [10], and poplar [11], respectively. The gene duplication events may increase the number of GRAS genes in these five plants. In this study, eight pairs of tandem duplication FtGRAS genes and five pairs of segmental duplication FtGRAS genes were detected (Fig. 3; Fig. 4). Our results further verify the effect of duplication on the expansion of the GRAS gene family. The contribution of tandem duplication to the expansion of Tartary buckwheat GRAS was greater than that of segmental duplication. Interestingly, we found some differences in the expression patterns of tandem duplicated genes (FtGRAS5 and FtGRAS6). The expression of FtGRAS6 in fruit was obviously lower than that of FtGRAS5. We further analyzed their expression during fruit development and found that the expression of FtGRAS6 decreased gradually with the development of fruit, but the expression pattern of FtGRAS5 was completely the opposite (Fig. 7a; Fig. 8a).
Comparison of motifs found that they contained the same motifs (motif 6, 7, 1, 4, 9, 3, 2, 5). By comparing their 3D structures, we observed a different random coil in the center of FtGRAS5 and FtGRAS6 protein (Additional file 1: Figure $S$ 1). Further comparison of their secondary structure showed mainly a difference in the random coil (Additional file 2: Figure S2). Therefore, the difference in the secondary structure or tertiary structure may lead to the functional difference of the protein. The duplicated genes may undergo different processes of selection (nonfunctionalization, neofunctionalization, or subfunctionalization), which may result in the diversity expression patterns or protein structures [55]. Therefore, we speculate that the two genes (FtGRAS5 and FtGRAS6) may have undergone different evolutionary processes, resulting in differences in protein structures and expression patterns during fruit development.

By analyzing the intron-exon structure of FtGRAS genes, we found that most of the FtGRAS genes (41, $87 \%)$ had no intron structure, which was similar to the 
results of tomato (77\%) [34], Prunus mume (83\%) [56], Chinese cabbage (83\%) [37], pepper (84\%) [2], and grapevine $(88.46 \%)$ [57]. The increase in genomic data and the establishment of more reliable models showed that the ancestors of each eukaryotic supergroup had intron-rich genes. The subsequent evolution of most eukaryotes involved the loss of introns [58]. The high proportion of intron-free genes in these plants (tomato, Prunus mume, Chinese cabbage, pepper, grapevine and Tartary buckwheat) suggests that they may have experienced intron loss events during evolution.

The domains and motifs of transcription factors play an important role in protein interaction and DNA binding [59]. GRAS contains five conserved domains at the Cterminus, all of which have important functions [4]. Ten different motifs were identified in Tartary buckwheat (Fig. 2c),and most of the FtGRAS genes contained motifs 6, 7, 1, 9, 3, 2, and 5. However, only LISCI, SHR, and PAT1 contained motif 4 (belonging to LHRII), which may mediate protein-protein interactions [4], suggesting that these subfamilies may have unique functions. Outside the domains of GRAS, we also found some conserved motifs, such as motif 10 (Fig. 2c, Additional file 4: Table S2), motifs 4 and 10 (Fig. 5, Additional file 4: Table S2). Motif 10 was only found in the HAM subfamily (Fig. 2c, Additional file 4: Table S2), which might confer a distinctive function to this subfamily.

\section{Predicting the potential functions of FtGRAS genes}

Intrinsically disordered proteins (IDPs) are biologically active proteins that do not form a fixed 3D structure under physiological conditions [60,61]. Depending on the particularities of the environment, an IDP can be folded into different structures to identify and bind diverse partners at different binding interfaces [62, 63]. With the use of computation and bioinformatics, it has been proven that GRAS protein is intrinsically disordered [60, 64]. A typical IDP of the GRAS protein is its highly variable N-terminus, which has short interacting fragments and molecular recognition features that are responsible for recognizing and binding specific partners to GRAS proteins [8]. IDP may lead to the functional differences in FtGRAS proteins.

By analyzing the expression pattern of FtGRAS gene in different plant tissues, we found a diverse transcript abundance of FtGRAS genes in different tissues and organs (Fig. 7a), implying that they might differ in function. Additionally homologous genes may have similar functions. FtGRAS23 showed a higher expression level in the flower, which is consistent with the expression pattern of the homologous gene ATSCL28 (AT1G63100), and SCL28 may play a sperm-specific role in Arabidopsis thaliana $[65,66]$. The transcription level of FtGRAS35 and the homologous gene ATSCL23 (AT5G41920) were both high in flower; ATSCL23 and SHR form negative a feedback loop, and the SHR-SCR-SCL23 module plays a key role in the formation of endodermis in Arabidopsis thaliana [66, 67]. FtGRAS32 is one of the gene that are homologous to the Arabidopsis thaliana gene PAT1 (AT5G48150.1). FtGRAS32 and PAT1 are highly expressed in fruit, and PAT1 is involved in PhyA signal transduction $[9,66]$. Simultaneously, we also found that most FtGRAS members expressed higher levels in early fruit development, which gradually decreased with fruit development. This situation is similar to GRAS in castor beans, indicating that these genes may be involved in early fruit development [53].

\section{DELLA subfamily and fruit development of Tartary buckwheat}

The DELLA subfamily is widely and extensively studied in the GRAS gene family, which are key regulators of the GA signal transduction pathway. DELLA protein inhibits plant growth and development, while GA promotes plant growth and development by degrading DELLA protein [68]. Degradation of DELLA is initiated by the formation of the GA-GID1-DELLA complex, which is then identified by the specific ubiquitin E3 ligase complex (SCFSLY1/ GID2), which marks the DELLA protein for degradation by the $26 \mathrm{~S}$ proteasome [68]. DELLA also plays an important role in the development of fruit [22-24]. To initially explore the relationship between GA and DELLA in Tartary buckwheat, we determined the content of endogenous GA during the development of buckwheat fruit (Fig. 8a), which decreased gradually from 13 to 19 DAP, reached the lowest value at $19 \mathrm{DAP}$, and then increased in the late stage of fruit development (19-25 DAP). Compared with the expression level of DELLA subfamily members (FtGRAS22, FtGRAS24, FtGRAS29), the expression level of FtGRAS22 in late fruit development (19 25 DAP) was opposite to that of GA. GA plays an important role in the late embryonic development of Arabidopsis thaliana, and the change in GA content in late embryonic development is opposite to the DELLA protein content [22]. Therefore, we speculate that FtGRAS22 may play a role in late fruit development. Interestingly, rice DELLA protein SLR1 (LOC-OS03g49990.1) can regulate cellulose synthesis by interacting with NAC transcription factors [25]. Cellulose is an important component of the plant cell wall, which can affect the cracking of Tartary buckwheat fruit $[69,70]$. We found that FtGRAS24 and FtGRAS29 were highly homologous to SLR1(Fig. 5), so we speculated that FtGRAS24 and FtGRAS29 might have similar functions to SLR1.

To further explore the relationship between DELLA genes and Tartary buckwheat fruit development, we sprayed paclobutrazol on the plants, a triazole plant growth regulator; the main biochemical function of 
paclobutrazol is to inhibit GA biosynthesis. The target enzyme of paclobutrazol is ent-kaurene oxidase (KO), which specifically inhibits the oxidation of ent-kaurene to ent-kaurene acid, thus hindering the synthesis of GA [71]. Then main morphological effects of paclobutrazol on plant growth include shortening the internode length, reducing the leaf area, increasing the leaf thickness, and increasing the flower bud number and fruit setting rate [72]. In this experiment, we observed a significant increase in the weight of Tartary buckwheat fruit by exogenous application of $160 \mathrm{mg} \mathrm{L}^{-1}$ paclobutrazol (Fig. 8b, c). We further measured the expression changes of the DELLA subfamily (FtGRAS22, FtGRAS24, FtGRAS29) upon treatment with paclobutrazol, an inhibitor of GA synthesis (Fig. 8d). Compared with the control group, the change in FtGRAS24 was not obvious, which suggested FtGRAS24 might not be sensitive to GA. FtGRAS29 increased significantly at 19 DAP, but it decreased significantly at 25DAP. The expression level of FtGRAS22 increased significantly during the whole fruit development period after paclobutrazol treatment. In conclusion, the sensitivity of FtGRA22 to GA was stronger than FtGRS24 and FtGRAS29. Thus, we speculate that FtGRAS22 may have an important impact on the development of Tartary buckwheat fruit and can be used as a candidate gene for Tartary buckwheat breeding.

Based on a preliminary analysis of DELLA subfamily members (FtGRAS22, FtGRAS24, FtGRAS29) in Tartary buckwheat, we found that the expression levels of the three genes and the sensitivity to GA during fruit development varied widely, suggesting that the three genes might be functionally different. DELLA protein can also be post-translationally modified by phosphorylation and O-Glc-Nac modification [73-77]. Post-translational modifications may lead to differences in function. Therefore, members of the DELLA subfamily in the same plant may also differ in function, and the mechanisms of DELLA protein and GA signal transduction in the process of Tartary buckwheat fruit development deserve further study.

\section{Conclusions}

In this study, 47 GRAS genes of Tartary buckwheat were identified and divided into 10 subfamilies: LISCL, HAM, DELLA, SCR, PAT1, SCL4/7, LAS, SHR, SCL3, and DLT. By analyzing the gene structure of FtGRAS, we found that most genes did not contain introns. Certain FtGRAS genes might have been produced by gene duplication; tandem duplication contributed more to the expansion of the GRAS gene family in Tartary buckwheat than did segmental duplication. The expression patterns of FtGRAS genes in different tissues (root, stem, leaf, flower, fruit) and fruit development stages (13, 19, 25
DAP) were further studied, indicating that they might have different functions in the growth and development of Tartary buckwheat. Furthermore, the increase in fruit weight was induced by exogenous paclobutrazol, and the transcription level of the DELLA subfamily member FtGRAS22 was significantly upregulated. Therefore, FtGRAS22 might be a potential target for molecular breeding or genetic editing. In conclusion, these findings provide a theoretical basis for studying the potential function of Tartary buckwheat GRAS genes.

\section{Methods}

\section{Plant growth}

The Tartary buckwheat variety used in this experiment was XIQIAO, which is a high rutin variety of Tartary buckwheat obtained by physical and chemical mutagenesis [78]. The Tartary buckwheat (XIQIAO) used in this study was provided by Professor Wang Anhu of Xichang University. From 2013 to 2018, XIQIAO was introduced into the experimental field of the College of Life Science, Sichuan Agricultural University, Ya'an, Sichuan, China, and the ecological environment and cultivation conditions were the same during those years. The materials were collected in 2017. The samples, including stem, root, leaf, flower and fruit at 13, 19, and 25 DAP were collected separately from 5 plants with good growth and similar growth conditions, and quickly placed in liquid nitrogen and stored at $-80^{\circ} \mathrm{C}$ for further use [27].

\section{Identification of GRAS genes in Tartary buckwheat}

Genes identification referred to the method of Liu et al. [27]. The genome of Tartary buckwheat was obtained from the Tartary Buckwheat Genome Project (TBGP; http://www.mbkbase.org/Pinku1/). First, all known AtGRAS proteins were used to query the initial protein on the TBGP website by BLASTp. Second, we downloaded the hidden Markov model (HMM) file corresponding to the GRAS domain (PF03514) from the Pfam protein family database (http://pfam.sanger.ac.uk/). The GRAS protein sequences of Tartary buckwheat were aligned using the HMM model in HMMER3.0. The existence of the GRAS core sequences was verified by the PFAM and SMART programs. Forty-seven GRAS genes were identified in the Tartary buckwheat genome. Finally, $47 \mathrm{FtGRAS}$ proteins were used as initial queries in the NCBI protein database (https://blast.ncbi.nlm.nih. gov/Blast.cgi? PROGRAM $=$ blastp\&PAGE_TYPE $=$ Blas tSearch\&LINK_LOC = blasthome) by BLASTp, further verifying that 47 proteins derived from Tartary buckwheat belonged to the GRAS gene family. The tools from the ExPASy website (https://web.expasy.org/protparam/) were used to obtain the sequence length, molecular weight, and isoelectric point of the identified GRAS protein. The subcellular localization of GRAS 
protein was predicted using CELLO (http://cello.life. nctu.edu.tw/).

\section{Phylogenetic analysis and classification of FtGRAS genes} The phylogenetic trees were derived using the Maximum Likelihood (ML) method. The AtGRAS and FtGRAS amino acid sequences were aligned using MUSCLE [79]. We used the JTT $+\mathrm{G}+\mathrm{F}$ model to identify the bestscoring tree in MEGA 7 [80]. The ML phylogenetic tree was constructed with 1000 bootstraps replicates. According to the classification of AtGRAS, all the identified FtGRAS genes were divided into different groups. The GRAS protein sequences (Arabidopsis thaliana, beet, soybean, grape, tomato, rice, sunflower) were downloaded from the UniProt database (https://www.uniprot. org), and phylogenetic trees were constructed with the above-described ML method.

\section{Gene structure and conserved motif analysis}

We used the gene structure display server (GSDS: http://gsds.cbi.pku.edu.cn) online program to analyze the exon-intron structure of the FtGRAS genes based on the CDS and the corresponding full-length sequence. The conserved motifs were studied in the encoded GRAS proteins to investigate the structural differences between the FtGRAS genes. We used the GRAS domain sequence of the FtGRAS proteins and default parameters of ClustalW to compare protein sequences. A MEME online program (http:/meme.nbcr.net/meme/intro.html) was used to analyze the protein sequences under the following parameters: the optimum motif width was $15 \sim 50$, and the maximum number of motifs was 10 .

\section{Chromosomal distribution and gene duplication of FtGRAS genes}

The physical location information was obtained from the Tartary buckwheat genomic database by Circos, and all FtGRAS genes were mapped to the chromosomes of Tartary buckwheat. Multiple collinear scanning toolkits (MCScanX) with default parameters were used to analyze gene duplication events. The syntenic relationship between FtGRAS genes and GRAS genes from selected plants was determined using Dual Synteny Plotter software.

\section{Structural prediction using protein modeling}

Putative protein sequences of 47 FtGRAS were used as query sequences. The secondary and tertiary structures of FtGRAS Protein were built using SOPMA (https:// npsa-prabi.ibcp.fr/cgi-bin/npsa_automat.pl?page $=$ npsa sopma.html) and SWISS-MODEL (https://www.swissmodel.expasy.org/interactive), respectively.

\section{Endogenous GA analysis and Paclobutrazol treatments} The determination method of endogenous GA in Tartary buckwheat was as follows: first, $0.5 \pm 0.01 \mathrm{~g}$ of fresh sample was collected and quickly ground in liquid nitrogen. The ground powder was homogenized in $80 \%$ methanol $(10 \mathrm{~mL})$ and stirred at $4{ }^{\circ} \mathrm{C}$ overnight. The supernatant was collected after centrifugation at $13900 \times g$ for 10 $\min$ at $4{ }^{\circ} \mathrm{C}$. The precipitate was washed once more by adding $80 \%$ methanol $(5 \mathrm{~mL})$, and the supernatant was collected after centrifugation. The mixed supernatant was evaporated at $36^{\circ} \mathrm{C}$ until no methanol remained. Second, $5 \mathrm{~mL}$ ultrapure water was used to wash the rotary evaporator bottle, and the rinsing solution was combined with the residual liquid. The solution was decolorized with diethyl ether three times, and then the water phase was collected and alkalized to $\mathrm{pH}$ 8.0. Next, the alkalized extract was mixed with $50 \mathrm{mg}$ of polyvinylpyrrolidone and then shaken for $30 \mathrm{~min}$. The supernatant was collected by centrifugation at $13900 \mathrm{x} g$ for $10 \mathrm{~min}$ at $4{ }^{\circ} \mathrm{C}$, followed by acidification to $\mathrm{pH} 3.0$ with citric acid. The ethyl acetate phase was collected by separating the solution three times with $5 \mathrm{~mL}$ of ethyl acetate. The combined ethyl acetate phases were evaporated to near dryness at $36^{\circ} \mathrm{C}$. Finally, the residue was dissolved in $1 \mathrm{~mL}$ of methanol. The final samples were analyzed by HPLC [27, 81, 82].

Paclobutrazol is a triazole plant growth regulator that can inhibit the concentration of GA in plants and is widely used in horticultural crops to shorten the internode length, reduce the leaf area, increase leaf thickness, and increase flower bud number and fruit set rate [83]. XIQIAO with similar growth statuses were selected and sprayed with $5 \mathrm{~mL}$ of different concentrations of paclobutrazol $\left(80,120,160,120\right.$ and $240 \mathrm{mg} \cdot \mathrm{L}^{-1}$ ) during the germination period. The same amount of water was sprayed as a blank control. Fruit samples were collected at 13, 19 and 25 DAP, respectively, frozen in liquid nitrogen and stored at $-80^{\circ} \mathrm{C}$ for further use.

Expression analysis of the FtGRAS genes by real-time PCR Total RNA was extracted using the RNAout Kit (TIANGEN, China) and treated with RNase free DNase I to remove trace amounts of DNA. According to the manufacturer's instructions, the cDNA was pretreated with the PrimeScript ${ }^{\mathrm{m}}$ 1st Strand cDNA Synthesis Kit (Japanese Takara). We obtained the corresponding sequences of these genes from the Tartary buckwheat (Pinku1) genome sequence database (http://www. mbkbase.org/Pinku1/) and then used Primer3 software (http://frodo.wi.mit.edu/) to design the RT-qPCR primers (Additional file 6: Table S4). Using the FtH3 gene as an internal control [84], standard RT-qPCR with SYBR Premix Ex Taq II (TaKaRa) was repeated at least three times on a CFX96 Real-Time System (BioRad). 
The data were analyzed by the $2^{-(\Delta \Delta \mathrm{Ct})}$ method, and the relative mRNA expression data were obtained [85].

\section{Statistical analysis}

The Origin Pro 2019b (OriginLab Corporation, Northampton, Massachusetts, USA) statistics program was used to analyze all the data by analysis of variance, and the means were compared by the least significant difference test (LSD) levels of significance.

\section{Additional files}

Additional file 1: Figure S1. Prediction of the 3D structures of 47 FtGRAS protein. (PNG $15359 \mathrm{~kb}$ )

Additional file 2: Figure S2. Secondary structures prediction of FtGRAS5 and FtGRAS6. (PNG $2066 \mathrm{~kb}$ )

Additional file 3: Table S1. List of the 47 FtGRAS genes identified in this study. (XLS $153 \mathrm{~kb}$ )

Additional file 4: Table S2. Analysis and distribution of conserved motifs in Tartary buckwheat GRAS proteins. (XLS $36 \mathrm{~kb}$ )

Additional file 5: Table S3. One-to-one orthologous relationships between Tartary buckwheat and other plants. (XLS $82 \mathrm{~kb}$ )

Additional file 6: Table S4. The primer sequences used for RT-qPCR. (XLS $39 \mathrm{~kb})$

\section{Abbreviations}

At: Arabidopsis thaliana; BLASTs: Basic local alignment search tools; CDS: Coding sequence length; DAP: Days after pollination; Ft: Fagopyrum tataricum; GA: Gibberellin; GAl: Gibberellic acid insensitive; IDPs: Intrinsically disordered proteins; LHRI: Leucine-rich region I; LHRII: Leucine-rich region II; LSD: Least significant difference test; MCScanX: Multiple collinear scanning toolkits; ML: Maximum Likelihood; Mw: Protein molecular weight; phyA: Phytochrome A; pl: Isoelectric point; RGA: Repressor of GA1-3 mutant; SCR: Scarecrow; TFs: Transcription factors

\section{Acknowledgements}

We thank all the colleagues in our laboratory for providing useful discussions and technical assistance. We are very grateful to the editor and reviewers for critically evaluating the manuscript and providing constructive comments for its improvement.

\section{Authors' contributions}

M.-YL planned and designed the research, and analyzed the data. LH wrote the original manuscript. LH and Z-TM determined the expression of genes by qRT-PCR. W-JS identified the FtGRAS family genes and visualized their structures. QW and Z-ZT performed the evolutionary analysis of FtGRAS genes and several different species. T-LB and C-LL performed the FtGRAS genes chromosome distribution, gene deplication and synchronous analyses. $H C, M-Y L$ and $L H$ reviewed and edited the manuscript. $H C$ supervised the research. M-YL and LH contributed equally. All authors read and approved the final manuscript.

\section{Funding}

This research was supported by the National Natural Science Foundation of China (31500289). Funds were used for the design of the study and collection, analysis, and interpretation of data and in writing the manuscript, as well as in the open access payment.

\section{Availability of data and materials}

The genome sequences of Tartary buckwheat used to identify the GRAS genes in this study are located in the Tartary Buckwheat Genome Project (TBGP; http://www.mbkbase.org/Pinku1/). The Tartary buckwheat accessions (XIQIAO; accessions number: CHUAN 2008013) used in the experiment were supplied by Professor Wang Anhu of Xichang University. These plant materials are widely used all over the world. and no permits are required for the collection of plant samples. The datasets supporting the conclusions of this article are included with in the article and its Additional files.

\section{Ethics approval and consent to participate}

The Tartary buckwheat (XIQIAO) used in this study was provided by Professor Wang Anhu of Xichang University. XIQIAO was introduced into the experimental field of the College of Life Science, Sichuan Agricultural University, Ya'an, Sichuan, China. The research conducted in this study required neither approval from an ethics committee, nor involved any human or animal subjects.

\section{Consent for publication}

Not applicable.

\section{Competing interests}

The authors declare that they have no competing interests.

\section{Author details}

${ }^{1}$ College of Life Science, Sichuan Agricultural University, Ya'an, China. ${ }^{2}$ School of Agriculture and Biology, Shanghai Jiao Tong University, Shanghai, China.

Received: 18 December 2018 Accepted: 29 July 2019

Published online: 06 August 2019

\section{References}

1. Riaño-Pachón DM, Ruzicic S, Dreyer I, Mueller-Roeber B. PInTFDB: an integrative plant transcription factor database. BMC Bioinformatics. 2007; 8(1):42-52.

2. Liu B, Sun Y, Xue J, Jia X, Li R. Genome-wide characterization and expression analysis of GRAS gene family in pepper (Capsicum annuum L.). PeerJ. 2018; 6(1):e4796-822.

3. Song Y, Xuan A, Bu C, Ci D, Tian M, Zhang D. Osmotic stress-responsive promoter upstream transcripts (PROMPTs) act as carriers of MYB transcription factors to induce the expression of target genes in Populus simonii. Plant Biotechnol J. 2019;17(1):164-77.

4. Pysh LD, Wysocka-Diller JW, Camilleri C, Bouchez D, Benfey PN. The GRAS gene family in Arabidopsis: sequence characterization and basic expression analysis of the SCARECROW-LIKE genes. Plant J. 1999;18(1):111-9.

5. Peng J, Carol P, Richards DE, King KE, Cowling RJ, Murphy GP, Harberd NP. The Arabidopsis GAl gene defines a signaling pathway that negatively regulates gibberellin responses. Genes Dev. 1997;23(11):3194-205.

6. Silverstone $A L$, Ciampaglio CN, Sun T. The Arabidopsis RGA gene encodes a transcriptional regulator repressing the gibberellin signal transduction pathway. Plant Cell. 1998;10(2):155-69.

7. Di Laurenzio L, Wysocka-Diller J, Malamy JE, Pysh L, Helariutta Y, Freshour G, Hahn MG, Feldmann KA, Benfey PN. The SCARECROW gene regulates an asymmetric cell division that is essential for generating the radial organization of the Arabidopsis root. Cell. 1996;3(86):423-33.

8. Sun X, Xue B, Jones WT, Rikkerink E, Dunker AK, Uversky VN. A functionally required unfoldome from the plant kingdom: intrinsically disordered $\mathrm{N}$ terminal domains of GRAS proteins are involved in molecular recognition during plant development. Plant Mol Biol. 2011;77(3):205-23.

9. Bolle C. The role of GRAS proteins in plant signal transduction and development. Planta. 2004;218(5):683-92.

10. Tian C, Wan P, Sun S, Li J, Chen M. Genome-wide analysis of the GRAS gene family in Rice and Arabidopsis. Plant Mol Biol. 2004;54(4):519-32.

11. Liu X, Widmer A. Genome-wide comparative analysis of the GRAS gene family in Populus, Arabidopsis and Rice. Plant Mol Biol Report. 2014; 32(6):1129-45.

12. Cenci A, Rouard M. Evolutionary analyses of GRAS transcription factors in angiosperms. Front Plant Sci. 2017;2(8):273-88

13. Torres-Galea P, Huang L-F, Chua N-H, Bolle C. The GRAS protein SCL13 is a positive regulator of phytochrome-dependent red light signaling, but can also modulate phytochrome a responses. Mol Gen Genomics. 2006;276(1):13-30.

14. Li M, Wang X, Li C, Li H, Zhang J, Ye Z. Silencing GRAS2 reduces fruit weight in tomato. J Integr Plant Biol. 2018;60(6):498-513.

15. Noriko K. The SCARECROW gene's role in asymmetric cell divisions in rice plants. Plant J. 2003;1(36):45-54.

16. Jeroen $\mathrm{S}$. Shoot meristem maintenance is controlled by a GRAS-gene mediated signal from differentiating cells. Genes Dev. 2002;17(16):2213-8. 
17. Sibylle H. GRAS proteins form a DNA binding complex to induce gene expression during nodulation signaling in Medicago truncatula. Plant Cell. 2009;2(21):545-57.

18. Wenqiang L. Identification and characterization of dwarf 62 , a loss-offunction mutation in DLT/OsGRAS-32 affecting gibberellin metabolism in rice. Planta. 2010;6(232):1383-96.

19. Yoshida H, Ueguchi-Tanaka M. DELLA and SCL3 balance gibberellin feedback regulation by utilizing INDETERMINATE DOMAIN proteins as transcriptional scaffolds. Plant Signal Behav. 2014;9(9):e29726-9.

20. Zhang B, Liu J, Yang ZE, Chen EY, Zhang CJ, Zhang XY, Li FG. Genome-wide analysis of GRAS transcription factor gene family in Gossypium hirsutum L. BMC Genomics. 2018;19(1):348-60.

21. Zhang H, Cao Y, Shang C, Li J, Wang J, Wu Z, Ma L, Qi T, Fu C, Bai Z, et al. Genome-wide characterization of GRAS family genes in Medicago truncatula reveals their evolutionary dynamics and functional diversification. PLoS One. 2017;12(9):e0185439-61.

22. Hu Y, Zhou L, Huang M, He X, Yang Y, Liu X, Li Y, Hou X. Gibberellins play an essential role in late embryogenesis of Arabidopsis. Nature Plants. 2018;4(5):289-98.

23. Martí C, Orzáez D, Ellul P, Moreno V, Carbonell J, Granell A. Silencing of DELLA induces facultative parthenocarpy in tomato fruits. Plant J. 2007; 52(5):865-76.

24. Hu J, Israeli A, Ori N, Sun TP. The interaction between DELLA and ARF/IAA mediates crosstalk between gibberellin and auxin signaling to control fruit initiation in tomato. Plant Cell. 2018;30(8):1710-28.

25. Huang D, Wang S, Zhang B, Shang-Guan K, Shi Y, Zhang D, Liu X, Wu K, Xu Z, Fu X, et al. A gibberellin-mediated DELLA-NAC signaling Cascade regulates cellulose synthesis in Rice. Plant Cell. 2015;27(6):1681-96.

26. Ahmed A, Khalid N, Ahmad A, Abbasi NA, Latif MSZ, Randhawa MA. Phytochemicals and biofunctional properties of buckwheat: a review. J Agric Sci. 2013;152(3):349-69.

27. Liu M, Ma Z, Wang A, Zheng T, Huang L, Sun W, Zhang Y, Jin W, Zhan J, Cai $Y$, et al. Genome-wide investigation of the auxin response factor gene family in Tartary buckwheat (Fagopyrum tataricum). Int J Mol Sci. 2018;19(11):3526-44.

28. Liu M, Fu Q, Ma Z, Sun W, Huang L, Wu Q, Tang Z, Bu T, Li C, Chen H. Genome-wide investigation of the MADS gene family and dehulling genes in tartary buckwheat (Fagopyrum tataricum). Planta. 2019;249(5):1301-18.

29. Liu M, Sun W, Ma Z, Zheng T, Huang L, Wu Q, Zhao G, Tang Z, Bu T, Li C. Genome-wide investigation of the AP2/ERF gene family in tartary buckwheat (Fagopyum Tataricum). BMC Plant Biol. 2019;19(1):84-103.

30. Liu M, Ma Z, Sun W, Huang L, Wu Q, Tang Z, Bu T, Li C, Chen H. Genomewide analysis of the NAC transcription factor family in Tartary buckwheat (Fagopyrum tataricum). BMC Genomics. 2019;20(1):113-29.

31. Liu M, Wen Y, Sun W, Ma Z, Huang L, Wu Q, Tang Z, Bu T, Li C, Chen H. Genome-wide identification, phylogeny, evolutionary expansion and expression analyses of bZIP transcription factor family in tartary buckwheat. BMC Genomics. 2019;20(1):483-501.

32. Liu M, Wang X, Sun W, Ma Z, Zheng T, Huang L, Wu Q, Tang Z, Bu T, Li C, et al. Genome-wide investigation of the ZF-HD gene family in Tartary buckwheat (Fagopyrum tataricum). BMC Plant Biol. 2019;19(1):248-62.

33. Liu M, Ma Z, Zheng T, Wang J, Huang L, Sun W, Zhang Y, Jin W, Zhan $J$, Cai $Y$, et al. The potential role of auxin and abscisic acid balance and FtARF2 in the final size determination of Tartary buckwheat fruit. Int J Mol Sci. 2018;19(9):2755-74.

34. Huang W, Xian Z, Kang X, Tang N, Li Z. Genome-wide identification, phylogeny and expression analysis of GRAS gene family in tomato. BMC Plant Biol. 2015;15(1):209-27.

35. Song L, Tao L, Cui H, Ling L, Guo C. Genome-wide identification and expression analysis of the GRAS family proteins in Medicago truncatula. Acta Physiol Plant. 2017;39(4):93-109.

36. Guo Y, Wu H, Li X, Li Q, Zhao X, Duan X, An Y, Lv W, An H. Identification and expression of GRAS family genes in maize (Zea mays L.). PLoS One. 2017;12(9):e0185418-35.

37. Song X-M, Liu T-K, Duan W-K, Ma Q-H, Ren J, Wang Z, Li Y, Hou X-L. Genome-wide analysis of the GRAS gene family in Chinese cabbage (Brassica rapa ssp. pekinensis). Genomics. 2014;103(1):135-46.

38. Zhang L, Li X, Ma B, Gao Q, Du H, Han Y, Li Y, Cao Y, Qi M, Zhu Y, et al. The Tartary buckwheat genome provides insights into Rutin biosynthesis and abiotic stress tolerance. Mol Plant. 2017;10(9):1224-37.

39. Holub EB. The arms race is ancient history in Arabidopsis, the wildflower. Nat Rev Genet. 2001;2(7):516-27.
40. Haibao T. Synteny and collinearity in plant genomes. Science. 2008; 5875(320):486-8.

41. Shen Y, Liu J, Geng H, Zhang J, Liu Y, Zhang H, Xing S, Du J, Ma S, Tian Z. De novo assembly of a Chinese soybean genome. Sci China Life Sci. 2018; 61(8):871-84.

42. Mahesh HB, Shirke MD, Singh S, Rajamani A, Hittalmani S, Wang G-L, Gowda $M$. Indica rice genome assembly, annotation and mining of blast disease resistance genes. BMC Genomics. 2016;17(1):242-54.

43. The Tomato Genome C, Sato S, Tabata S, Hirakawa H, Asamizu E, Shirasawa K, Isobe S, Kaneko T, Nakamura Y, Shibata D, et al. The tomato genome sequence provides insights into fleshy fruit evolution. Nature. 2012; 485(7400):635-41.

44. Roach MJ, Johnson DL, Bohlmann J, van Vuuren HJJ, Jones SJM, Pretorius IS, Schmidt SA, Borneman AR. Population sequencing reveals clonal diversity and ancestral inbreeding in the grapevine cultivar chardonnay. PLoS Genet. 2018;14(11):e1007807-31.

45. Schneeberger K, Ossowski S, Ott F, Klein JD, Wang X, Lanz C, Smith LM, Cao J, Fitz J, Warthmann N, et al. Reference-guided assembly of four diverse Arabidopsis thaliana genomes. Proc Natl Acad Sci. 2011;108(25):10249-54.

46. Dohm JC, Minoche AE, Holtgräwe D, Capella-Gutiérrez S, Zakrzewski F, Tafer $H$, Rupp O, Sörensen TR, Stracke R, Reinhardt R, et al. The genome of the recently domesticated crop plant sugar beet (Beta vulgaris). Nature. 2013; 505(7484):546-9.

47. Badouin H, Gouzy J, Grassa CJ, Murat F, Staton SE, Cottret L, Lelandais-Brière C, Owens GL, Carrère S, Mayjonade B, et al. The sunflower genome provides insights into oil metabolism, flowering and Asterid evolution. Nature. 2017; 546(7656):148-52.

48. Lee C-C, Shen S-R, Lai Y-J, Wu S-C. Rutin and quercetin, bioactive compounds from tartary buckwheat, prevent liver inflammatory injury. Food Funct. 2013:4(5):794-802.

49. Liu M, Ma Z, Zheng T, Sun W, Zhang Y, Jin W, Zhan J, Cai Y, Tang Y, Wu Q, et al. Insights into the correlation between physiological changes in and seed development of tartary buckwheat (Fagopyrum tataricum Gaertn.). BMC Genomics. 2018;19(1):648-68.

50. Swain MS, Reid J, Kamiya Y. Gibberellins are required for embryo and seed development in pea. Plant J. 2002;12(6):1329-38.

51. Hedden P, Graebe EJ. Inhibition of gibberellin biosynthesis by paclobutrazol in cell-free homogenates of Cucurbita-Maxima endosperm and Malus pumila embryos. J Plant Growth Regul. 1985;4(1):111-22.

52. Yeshitela T, Robbertse P, Stassen PJC. Paclobutrazol suppressed vegetative growth and improved yield as well as fruit quality of 'Tommy Atkins' mango (Mangifera indica) in Ethiopia. NZ J Crop Hortic Sci. 2004;32(3):281-93.

53. Xu W, Chen Z, Ahmed N, Han B, Cui Q, Liu A. Genome-wide identification, evolutionary analysis, and stress responses of the GRAS gene family in Castor beans. Int J Mol Sci. 2016;17(7):1004-20.

54. Zhang D, lyer L, Aravind L. Bacterial GRAS domain proteins throw new light on gibberellic acid response mechanisms. Bioinformatics. 2012;28(19):2407-11.

55. Victoria EP. Splitting pairs: the diverging fates of duplicated genes. Nat Rev Genet. 2002;3(11):827-37.

56. Jiuxing L. Genome-wide analysis of the GRAS gene family in Prunus mume. Mol Gen Genomics. 2015:1(290):303-17.

57. Grimplet J, Agudelo-Romero P, Teixeira RT, Martinez-Zapater JM, Fortes AM. Structural and functional analysis of the GRAS gene family in grapevine indicates a role of GRAS proteins in the control of development and stress responses. Front Plant Sci. 2016;7(353):e39547-80.

58. Rogozin IB, Carmel L, Csuros M, Koonin EV. Origin and evolution of spliceosomal introns. Biol Direct. 2012;7(1):11-39.

59. Liu L, White MJ, TH MR. Transcription factors and their genes in higher plants functional domains, evolution and regulation. Eur J Biochem. 1999;262(2):247-57.

60. Uversky VN, Gillespie JR, Fink AL. Why are "natively unfolded" proteins unstructured under physiologic conditions? Proteins. 2000;41(3):415-27.

61. Wright $P$. Intrinsically unstructured proteins: re-assessing the protein structure-function paradigm. J Mol Biol. 1999;293(2):321-31.

62. Uversky V, Oldfield C, Keith Dunker A. Showing your ID: intrinsic disorder as an ID for recognition, regulation and cell signaling. J Mol Recognit. 2005;18(5):343-84

63. Peter EW. Linking folding and binding. Curr Opin Struct Biol. 2009:19(1):31-8.

64. Dunker AK, Lawson JD, Brown CJ, Williams RM, Romero P, Oh JS, Oldfield CJ, Campen AM, Ratliff CM, Hipps KW, et al. Intrinsically disordered protein. J Mol Graphics Modell. 2001;19(1):26-59. 
65. Filipe B. Comparative transcriptomics of Arabidopsis sperm cells. Plant Physiol. 2008;148(2):1168-81.

66. Mi-Hyun L. Large-scale analysis of the GRAS gene family in Arabidopsis thaliana. Plant Mol Biol. 2008:67(6):659-70.

67. Yoon EK, Dhar S, Lee MH, Song JH, Lee SA, Kim G, Jang S, Choi JW, Choe JE, Kim JH, et al. Conservation and diversification of the SHR-SCR-SCL23 regulatory network in the development of the functional endodermis in Arabidopsis shoots. Mol Plant. 2016;9(8):1197-209.

68. Wang Y, Deng D. Molecular basis and evolutionary pattern of GA-GID1DELLA regulatory module. MGG Mol Gen Genet. 2013;289(1):1-9.

69. Chanliaud E. Mechanical effects of plant cell wall enzymes on cellulose/ xyloglucan composites. Plant J. 2004;38(1):27-37.

70. Yamaki S, Matsuda K. Changes in the activities of some cell wall-degrading enzymes during development and ripening of Japanese pear fruit (Pyrus serotina Rehder var. Culta rehder). Plant Cell Physiol. 1977;18(1):81-93.

71. Hedden P. Gibberellin metabolism and its regulation. J Plant Growth Regul. 2001;20(4):317-8.

72. Zhu L, Beijing C, Cao Q, Li M. The effect of Paclobutrazol on the growth and development of walnut and its physiological mechanism. For Res. 1993;6(5):531-5.

73. Sasaki A, Itoh H, Gomi K, Ueguchi-Tanaka M, Ishiyama K, Kobayashi M, Jeong D-H, An G, Kitano H, Ashikari M, et al. Accumulation of phosphorylated repressor for gibberellin signaling in an F-box mutant. Science. 2003; 299(5614):1896-8.

74. Fu X. The Arabidopsis mutant sleepy1 (gar2-1) protein promotes plant growth by increasing the affinity of the SCF (SLY1) E3 ubiquitin ligase for DELLA protein substrates. Plant Cell. 2004;6(16):1406-18.

75. Gomi K. GID2, an F-box subunit of the SCF E3 complex, specifically interacts with phosphorylated SLR1 protein and regulates the gibberellin-dependent degradation of SLR1 in rice. Plant J. 2004;37(4):626-34.

76. Hussain A, Cao D, Cheng H, Wen Z, Peng J. Identification of the conserved serine/threonine residues important for gibberellin-sensitivity of Arabidopsis RGL2 protein. Plant J. 2005;44(1):88-99.

77. Itoh H, Sasaki A, Ueguchi-Tanaka M, Ishiyama K, Kobayashi M, Hasegawa Y, Minami E, Ashikari M, Matsuoka M. Dissection of the phosphorylation of rice DELLA protein, SLENDER RICE1. Plant Cell Physiol. 2005:46(8):1392-9.

78. Wang AHXM, Cai GZ, Dai HY. Buckwheat new variety Xiqiao no.2 with high yield and excellent quality. Seed. 2009;28(10):110-2.

79. Edgar RC. MUSCLE: multiple sequence alignment with high accuracy and high throughput. Nucleic Acids Res. 2004:32(5):1792-7.

80. Kumar S, Stecher G, Tamura K. MEGA7: molecular evolutionary genetics analysis version 7.0 for bigger datasets. Mol Biol Evol. 2016;33(7):1870-4.

81. Xu X, van Lammeren AAM, Vermeer E, Vreugdenhil D. The role of gibberellin, abscisic acid, and sucrose in the regulation of potato tuber formation in vitro. Plant Physiol. 1998;117(2):575-85.

82. Mwange KN, Hou HW, Cui KM. Relationship between endogenous indole-3acetic acid and abscisic acid changes and bark recovery in Eucommia ulmoides Oliv. After girdling. J Exp Bot. 2003;54(389):1899-907.

83. Kamran M, Wennan S, Ahmad I, Xiangping M, Wenwen C, Xudong Z, Siwei M, Khan A, Qingfang H, Tiening L. Application of paclobutrazol affect maize grain yield by regulating root morphological and physiological characteristics under a semi-arid region. Sci Rep. 2018;8(1):4818-33.

84. Li C, Zhao H, Li M, Yao P, Li Q, Zhao X, Wang A, Chen H, Tang Z, Bu T, et al. Validation of reference genes for gene expression studies in tartary buckwheat (Fagopyrum tataricum Gaertn.) using quantitative real-time PCR. PeerJ. 2019;7:e6522-37.

85. Livak KJ, Schmittgen TD. Analysis of relative gene expression data using realtime quantitative $P C R$ and the 2- $\Delta \Delta C T$ method. Methods. 2001;25(4):402-8.

\section{Publisher's Note}

Springer Nature remains neutral with regard to jurisdictional claims in published maps and institutional affiliations.

Ready to submit your research? Choose BMC and benefit from:

- fast, convenient online submission

- thorough peer review by experienced researchers in your field

- rapid publication on acceptance

- support for research data, including large and complex data types

- gold Open Access which fosters wider collaboration and increased citations

- maximum visibility for your research: over $100 \mathrm{M}$ website views per year

At BMC, research is always in progress.

Learn more biomedcentral.com/submissions 